European Federation of Societies for Ultrasound in Medicine and Biology

\title{
Prenatal Ultrasound and Autism: A Prediction Tool, a Risk Factor, Both or Neither?
}

Kimon Chatzistamatiou, Eleni Tsepkentzi, Konstantinos Dinas, Alexandros Sotiriadis Second Department of Obstetrics and Gynecology (KC, KD, AS) and First Department of Pediatrics (ET), Aristotle University of Thessaloniki, Greece

E-mail: asotir@gmail.com

Ensuring a favorable long-term neurodevelopmental outcome for the offspring has become a major objective in current Maternal - Fetal Medicine. To this end, autism remains a blind spot, and there are many reasons for this, including its clinical heterogeneity (autism spectrum disorders, ASD) and the lack of a single identifiable cause [1-3]. Instead, various prenatal, perinatal and postnatal factors, often contradictory to each other, have been reported to statistically increase the risk for autism $[4,5]$.

Studies on ultrasound and autism are sporadically published, examining their relationship in two contexts, i. e. in the context of fetal ultrasound as a prediction tool for the development of autism in infant life, and in the context of prenatal ultrasound as a risk factor for autism.

The rationale for identifying fetuses at risk for ASD is that intervention in early infancy, before the onset of symptoms, may improve their outcomes in a cost-effective way [6, 7]. Therefore, given that atypical postnatal head growth trajectories had been reported in children with ASD [8, 9], fetal growth has been an obvious candidate ultrasound marker for prenatal prediction of autism. A population-based Swedish case-control study comparing fetal growth of more than 4,000 children with ASD to more than 36,000 matched controls identified increased risk for ASD for both children with decreased fetal growth (less than two standard deviations below the mean), and children with excessive fetal growth (more than two standard deviations above the mean). Moreover, preterm birth was independently associated with ASD, regardless of fetal growth [10]. Therefore, screening for and prevention of preterm birth at midtrimester scan could theoretically modify one of the risk factors for ASD. Second-trimester fetal growth may not be as an accurate predictor; two small case-control studies reported no difference between ASD cases and controls in fetal growth parameters, i. e. head circumference (HC) at 18 weeks [11] and second trimester biparietal diameter (BPD), abdominal circumference (AC) and femoral length (FL) [12]. Notably, the latter study reported a significant AC decrease in the subgroup of patients with multiplex ASD, i. e. ASD with schizophrenic symptoms [12].

There are several minor physical findings in children with ASD. Some of these (e.g. increased volume of the cerebellum, increased volume of the cerebral ventricles, high steeped or narrow palate and decreased second to fourth digit length ratio) may be assessed prenatally by ultrasound imaging, defining a fetus as potentially at increased risk for autism [13]. However, these findings are not consistent and represent mere associations, as does fetal gender, in that male fetuses could be four to five times more likely to have ASD in childhood than female ones.

Quite recently, a registry-based Danish study (unselected cohort of more than 220,000 euploid foetuses; follow-up to the age of 4.4 years) reported that nuchal translucency above the 99th percentile was associated to 2.48 times increased odds for the development of ASD. The association was stronger (OR2.60) when children with structural malformations were excluded. Still, the absolute risk was very low overall $(<1 \%)$ [14].

However, as strong as a statistical association may be for certain findings, there are three debilitating problems with ultrasound-based markers: (i) they have low specificity, in that they are commonly found in foetuses with normal development, (ii) they do not have an apparent etiological link with autism and (iii) there is no confirmatory test for foetuses identified as at high risk.

Regarding the potential role of prenatal ultrasound itself as a causative factor for autism, a statistical concern has arisen by the observation that ASD prevalence increases in parallel with the increase of global antenatal ultrasound use [15]. This issue was extensively discussed in a 2012 review [16]. The first axis for this discussion focused on the fact that ultrasound as a form of energy can have certain effects on live tissue [17]. For example, there are animal data indicating that prolonged ultrasound exposure can affect neuron migration during the development of the central nervous system [18]. No such effects have been demonstrated in humans, and the only effect of antenatal ultrasound possibly associated to a CNS-related phenomenon would be the weak association of nonright-handedness in boys, as it has been reported by the ISUOG-WHO fetal growth study group [19]. However, just being male would increase the risk for ASD by four to five times. The author of the review concludes that there is no evidence of a causal relationship between antenatal ultrasound and autism [16]. A larger cohort 
study in Sweden also failed to connect ASD to prenatal ultrasound examination at 12 or 18 weeks of gestation. The authors noted that, at the time of their study (19992003), prenatal ultrasound exposure used to be less frequent and utilized lower intensities than in later time, underlining the need for more research on higher prenatal ultrasound exposure [20]. This question was addressed by Stoch et al., who studied pregnancies with intensive prenatal ultrasound exposure (five examinations throughout pregnancy) compared to regular exposure (one single examination at 18 weeks of gestation and further scans as medically indicated). During their 20-yearfollow up, no significant link was found between the timing and frequency of ultrasound examination and ASD [21].

So far, the only effect prenatal ultrasound exposure seems to have on human fetuses is a weak link to non-right-handedness. The biological effects shown on mice were not documented in studies on human fetuses and this might have happened because (a) the dosage and duration of in utero exposure was larger in animals compared to humans, (b) human tissues may be more resistant to ultrasound than those of mice, (c) the duration of intrauterine exposure was longer in animals compared to the shorter exposure throughout a 40 week gestation in humans and (d) it is not possible to have a direct comparison of ASD between humans and animals, as we can only discuss the possibility of autistic-like behaviour in the latter [22].

Based on current data, there is no evidence of association between prenatal exposure to ultrasound and ASD. Apart from finding a causative pathway, a potential link between prenatal ultrasound and ASD would require adjusting for technical parameters (e. g. frequency, time of exposure, probes used, thickness of abdominal wall - BMI, number of examinations, B-mode, Doppler etc) and also for significant confounders (e. g. conditions that have themselves been associated to autism, requiring more intensive ultrasound follow-up). Regarding the potential use of ultrasound for autism screening, technical limitations in imaging the fine structures of the fetal brain, together with evidence of later-onset postnatal changes, severely limits its sensitivity and specificity and, collectively, its feasibility as a screening tool.

\section{References}

[1] Newschaffer C], Curran LK. Autism: an emerging public health problem. Public Health Rep 2003; 118: 393 - 399 [published Online First: Epub Date]

[2] Kuehn BM. Data on autism prevalence, trajectories illuminate socioeconomic disparities. JAMA 2012; 307: 2137-2138 [published Online First: Epub Date]

[3] Blaxill MF. What's going on? The question of time trends in autism. Public Health Rep 2004; 119: 536-551 [published Online First: Epub Date]

[4] Gardener H, Spiegelman D, Buka SL. Perinatal and neonatal risk factors for autism: a comprehensive meta-analysis. Pediatrics 2011; 128: 344 - 355 [published Online First: Epub Date]

[5] Wang C, Geng H, Liu W et al. Prenatal, perinatal, and postnatal factors associated with autism: A meta-analysis. Medicine (Baltimore) 2017; 96: e6696 [published Online First: Epub Date]

[6] Penner M, Rayar M, Bashir N et al. Cost-Effectiveness Analysis Comparing Pre-diagnosis Autism Spectrum Disorder (ASD)-Targeted Intervention with Ontario's Autism Intervention Program. J Autism Dev Disord 2015; 45: 2833-2247 [published Online First: Epub Date]

[7] McPheeters ML, Weitlauf A, Vehorn A et al. Screening for Autism Spectrum Disorder in Young Children: A Systematic Evidence Review for the US Preventive Services Task Force. Rockville (MD), 2016

[8] Fukumoto A, Hashimoto $\mathrm{T}$, Ito $\mathrm{H}$ et al. Growth of head circumference in autistic infants during the first year of life. J Autism Dev Disord 2008; 38: 411-418 [published Online First: Epub Date]

[9] Elder LM, Dawson G, Toth K et al. Head circumference as an early predictor of autism symptoms in younger siblings of children with autism spectrum disorder. J Autism Dev Disord 2008; 38: 1104-1111 [published Online First: Epub Date]
[10] Abel KM, Dalman C, Svensson AC et al. Deviance in fetal growth and risk of autism spectrum disorder. Am J Psychiatry 2013; 170 (4): $391-8$ [published Online First: Epub Date]

[11] Whitehouse AJ, Hickey M, Stanley FJ et al. Brief report: a preliminary study of fetal head circumference growth in autism spectrum disorder. J Autism Dev Disord 2011; 41: 122 129 [published Online First: Epub Date]

[12] Hobbs K, Kennedy A, Dubray M et al. A retrospective fetal ultrasound study of brain size in autism. Biol Psychiatry 2007; 62: 1048-1055 [published Online First: Epub Date]

[13] Gamliel M, Ebstein R, Yirmiya N et al. Minor fetal sonographic findings in autism spectrum disorder. Obstet Gynecol Surv 2012; 67: 176-186 [published Online First: Epub Date]

[14] Hellmuth SG, Pedersen LH, Miltoft CB et al. Increased nuchal translucency thickness and risk of neurodevelopmental disorders. Ultrasound Obstet Gynecol 2016. doi:10.1002/ uog.15961 [published Online First: Epub Date]

[15] Rodgers C. Questions about prenatal ultrasound and the alarming increase in autism. Midwifery Today Int Midwife 2006; 80: 16-19, 66-67

[16] Abramowicz JS. Ultrasound and autism: association, link, or coincidence? J Ultrasound Med 2012; 31 (8): $1261-1269$

[17] Abramowicz JS. Prenatal exposure to ultrasound waves: is there a risk? Ultrasound Obstet Gynecol 2007; 29: 363-367 [published Online First: Epub Date]

[18] Ang ES Jr. Gluncic V, Duque A et al. Prenatal exposure to ultrasound waves impacts neuronal migration in mice. Proc Natl Acad Sci U S A 2006; 103: 12903 - 12910 [published Online First: Epub Date]

[19] Torloni MR, Vedmedovska N, Merialdi M et al. Safety of ultrasonography in pregnancy: WHO systematic review of the literature and metaanalysis. Ultrasound Obstet Gynecol 2009; 33: 599-608 [published Online First: Epub Date]

[20] Hoglund Carlsson L, Saltvedt S, Anderlid BM et al. Prenatal ultrasound and childhood autism: long-term follow-up after a randomized controlled trial of first- vs second-trimester ultrasound. Ultrasound Obstet Gynecol 2016; 48: 285-288 [published Online First: Epub Date]

[21] Stoch YK, Williams C], Granich J et al. Are prenatal ultrasound scans associated with the autism phenotype? Follow-up of a randomised controlled trial. J Autism Dev Disord 2012; 42: 2693- 2701 [published Online First: Epub Date]

[22] McClintic AM, King BH, Webb S] et al. Mice exposed to diagnostic ultrasound in utero are less social and more active in social situations relative to controls. Autism Res 2014; 7: $295-$ 304 [published Online First: Epub Date] 